\title{
Musculoskeletal problems during pregnancy
}

\author{
Fulya Bakilan', Demet Demiray Zelveci \\ ${ }^{I}$ Physical Medicine and Rehabilitation Department, Eskisehir City Hospital, Eskisehir, Turkey \\ ${ }^{2}$ Obstetrics and Gynecology Department, Özel Çorum Hastanesi, Çorum, Turkey
}

Received: 2020-08-04.

Accepted: 2020-08-19

This work is licensed under a reative Commons Attribution 4.0 International License

\section{J Clin Med Kaz 2020; 6(60):53-55}

Corresponding author:

Fulya Bakılan.

E-mail: fulyabakilan@gmail.com;

ORCID: 0000000329434833

\section{Abstract}

Objective: The prevalence of musculoskeletal problems in pregnancy can vary according to trimester. Early diagnosis and treatments are important to prevent the development of chronic problems. This study was conducted to identify the most common musculoskeletal problems according to trimester, experienced by pregnant women.

Material and methods: A total of 120 pregnant women who admitted to physical medicine and rehabilitation clinic, evaluated retrospectively in this study. Application complaints, the diagnosis and the trimester of the pregnant women and also age, weight, height, number of pregnancy, working status, presence of secondary disease were recorded.

Results: In the first trimester, the most experienced musculoskeletal problems were low back pain (26.3\%), pelvic girdle pain (26.3\%) and carpal tunnel syndrome (26.3\%). The most frequent problem in the second trimester was lower back pain (43.6\%) followed by cramp (32.7\%) and pelvic girdle pain (30.9\%). Finally, in the third trimester, low back pain (34.8\%), cramp (32.6\%) and pedal edema (32.6\%) were the most reported problems.

Conclusion: The prevalence of musculoskeletal problems in pregnancy can vary according to socio-cultural and environmental factors. Determining the most common musculoskeletal problems experienced in pregnancy in a specific region is important for early diagnosis, increasing quality of life and preventing the development of chronic disorders. pain

Key words: carpal tunnel syndrome, low back pain, pelvic girdle

\section{Introduction}

Hormonal and physiological changes occurring during pregnancy can cause numerous musculoskeletal problems such as lower back pain, carpal tunnel syndrome and tendinitis. An overview of the literature shows that the most common problem is low back pain in pregnancy, the incidence was found to be from $30 \%$ to $70 \%$ [1-4]. The second most common musculoskeletal problem has been reported as carpal tunnel syndrome [5]. Another problem experienced in pregnancy is muscle cramp which mostly occurs during sleep and only lasting a few seconds [6].

The prevalence of musculoskeletal problems in pregnancy can vary according to socio-cultural and environmental factors. Heavy housework and working conditions, having many children, depression, anxiety and also violence can trigger many musculoskeletal problems. Early diagnosis and treatment of musculoskeletal problems in pregnancy is significantly important in order to increase the quality of life and prevent the development of chronic disorders.

Determining the most common musculoskeletal problems experienced by pregnant women living in a specific region is beneficial to physicians in monitoring patient progress during routine checks and facilitating early diagnosis and treatment when necessary. All untreated musculoskeletal problems, such as low back pain, carpal tunnel syndrome further impairs the quality of life of pregnant women $[1,5]$. To examine the musculoskeletal problems in routine checks, it is important to know which problems are in common in which trimester. This study was carried out to identify the most common musculoskeletal problems according to trimester, as experienced by pregnant women.

\section{Material and methods}

One hundred and twenty pregnant women who is older than 18, attending the Physical Medicine and Rehabilitation Clinic between January- May 2015, were evaluated retrospectively. All procedures performed in studies involving human participants were in accordance with the ethical standards of the institutional and/or national research committee and with the 1964 Helsinki declaration 
and its later amendments or comparable ethical standards (2104-20 / 02 - 25403353-05099-E.46802).

Pregnant patients who have age, weight, size, employment status, duration of pregnancy, nulli/multi-parity, presence of other disorders, application complaints, the diagnosis information were included to the study.

Application complaints (such as pain, numbness, tingling, swelling and cramps), the diagnosis (low back pain, pelvic girdle pain, carpal tunnel syndrome, pedal edema, cramp, knee pain, foot pain, neck pain) of the pregnant patients were recorded. And also the demographic characteristics of the patients comprising age, weight, size, employment status, duration of pregnancy, nulli/multi-parity, and presence of other disorders (gestational diabetes, hypertension) were recorded.

The first, second and third trimesters were defined as gestational weeks 1 to 13,14 to 26 and 27 to 40 , respectively.

\section{Results}

Table 1 presents the demographic characteristics of the participants.

Table 1

The demographic characteristics of the pregnant women who have musculoskeletal problems.

\begin{tabular}{|l|l|}
\hline & 120 pregnant women $-\mathrm{n}(\%)$ \\
\hline Age $($ mean \pm SD) & $26.98 \pm 6.02$ \\
\hline Weight $($ mean \pm SD) $(\mathrm{kg})$ & $72,65 \pm 13.36$ \\
\hline Height $($ mean \pm SD) $(\mathrm{cm})$ & $161.89 \pm 6,70$ \\
\hline Socioeconomic status & \\
\hline \multicolumn{1}{|c|}{ Working } & $12(10 \%)$ \\
\hline Not working & $108(90 \%)$ \\
\hline Presence of gestational diabetes & $1(0.8 \%)$ \\
\hline Presence of chronic disease & $11(9,2 \%)$ \\
\hline Parity & \\
\hline Nulliparity & $44(36.7 \%)$ \\
\hline Multiparity & $76(63.3 \%)$ \\
\hline Total & $120(100 \%)$ \\
\hline
\end{tabular}

(SD: standard deviation)

\begin{tabular}{|c|c|c|c|c|}
\hline \multirow[t]{2}{*}{ Table 2} & \multicolumn{4}{|c|}{$\begin{array}{l}\text { Prevalence of musculoskeletal problems } \\
\text { according to trimesters. }\end{array}$} \\
\hline & $\begin{array}{l}\text { 1st } \\
\text { Trimester } \\
\mathrm{n}(\%)\end{array}$ & $\begin{array}{l}\text { 2nd } \\
\text { Trimester } \\
\mathrm{n}(\%)\end{array}$ & $\begin{array}{l}\text { 3rd } \\
\text { Trimester } \\
\text { n (\%) }\end{array}$ & $\begin{array}{l}\text { Total } \\
\mathrm{n}(\%)\end{array}$ \\
\hline Cramp & $4(21.1 \%)$ & $18(32.7 \%)$ & $15(32.6 \%)$ & 37 (30.8\%) \\
\hline Low-back pain & $5(26.3 \%)$ & $24(43.6 \%)$ & $16(34.8 \%)$ & $45(37.5 \%)$ \\
\hline $\begin{array}{l}\text { Pelvic-girdle } \\
\text { pain }\end{array}$ & $5(26.3 \%)$ & $17(30.9 \%)$ & $13(28.3 \%)$ & $35(29.2 \%)$ \\
\hline $\begin{array}{l}\text { Carpal Tunnel } \\
\text { Syndrome }\end{array}$ & $5(26.3 \%)$ & $9(16.4 \%)$ & $13(28.3 \%)$ & $27(22.5 \%)$ \\
\hline Coccydynia & $1(5.3 \%)$ & $1(1.8 \%)$ & $0(0 \%)$ & $2(1.7 \%)$ \\
\hline Pedal Edema & $3(15.8 \%)$ & $10(18.2 \%)$ & $15(32.6 \%)$ & $28(23.3 \%)$ \\
\hline Foot pain & $0(0 \%)$ & $0(0 \%)$ & $1(2.2 \%)$ & $1(0.8 \%)$ \\
\hline $\begin{array}{l}\text { Upper back } \\
\text { pain }\end{array}$ & $3(15.8 \%)$ & $8(14.5 \%)$ & $8(17.4 \%)$ & $19(15.8 \%)$ \\
\hline Neck pain & $1(5.3 \%)$ & $0(0 \%)$ & $2(4.3 \%)$ & $3(2.5 \%)$ \\
\hline $\begin{array}{l}\text { Knee joint } \\
\text { pain }\end{array}$ & $1(5.3 \%)$ & $5(9.1 \%)$ & $1(2.2 \%)$ & $7(5.8 \%)$ \\
\hline $\begin{array}{l}\text { De quervain } \\
\text { tendinitis }\end{array}$ & $0(0 \%)$ & $3(5.5 \%)$ & $1(2.2 \%)$ & $4(3.3 \%)$ \\
\hline Trigger finger & $1(5.3 \%)$ & $0(0 \%)$ & $1(2.2 \%)$ & $2(1.7 \%)$ \\
\hline Hip pain & $2(10.5 \%)$ & $1(1.8 \%)$ & $2(4.3 \%)$ & $5(4.2 \%)$ \\
\hline Calf pain & $2(10.5 \%)$ & $3(5.5 \%)$ & $4(8.7 \%)$ & $9(7.5 \%)$ \\
\hline Total & $19(100 \%)$ & $55(100 \%)$ & $46(100 \%)$ & $\begin{array}{l}120 \\
(100 \%)\end{array}$ \\
\hline
\end{tabular}

According to the gestational period; $19(15,8 \%)$ of 120 pregnant women were in the first trimester, $55(45,8 \%)$ of them were in the second and $46(38,23 \%)$ of them were in the third trimester. In the first trimester, the most experienced musculoskeletal problems were; lower back pain $(26.3 \%)$, pelvic girdle pain (26.3\%) and carpal tunnel syndrome $(26.3 \%)$. In the second trimester, the most reported problem was lower back pain (43.6\%) followed by cramp (32.7\%) and pelvic girdle pain $(30.9 \%)$. Finally, in the third trimester, lower back pain $(34.8 \%)$, cramp $(32.6 \%)$ and pedal edema (32.6\%) were commonly observed.

Table 2 presents all the reported musculoskeletal problems according to trimesters.

\section{Discussion}

The most frequent musculoskeletal pathology was lower back pain $(66.7 \%)$ in pregnant women that were admitted to Physical Therapy and Rehabilitation Clinic. These results are consistent with the results obtained from several studies in the literature. In one study, lower back pain was reported in $68.8 \%$ of the 105 mothers who had given birth within the last 6 months [7] and in another study it was reported 79.8\% [8]. Not only in pregnancy but also in other patients, low back pain was reported the most common reason for admission by a pain clinic [9].

The most important factors implicated in the etiology of low back pain are; the center of gravity shifting to the front due to weight gain and the growth of the uterus, and the relaxation of the joints due to the increased relaxin levels [10]. These findings are in alignment with those of our study in terms of low back pain and pelvic girdle pain was most observed in the second trimester. Similarly, Ramachandra et al., conducting a study of 261 primipara cases, found the highest prevalence of low back pain and pelvic girdle pain in the second trimester [11]. The decrease in the prevalence of back pain in the third trimester can be attributed to the increased need for rest resulting from the various changes that occur during pregnancy.

In our study, the second most common musculoskeletal problem was cramp this was mostly reported in the second and third trimesters. These cramps mostly occur during sleep in the second half of pregnancy and last for only a few seconds. In the etiology of cramps during pregnancy, magnesium and calcium deficiency are mostly implicated [6]. A study in Kazakhstan showed that pregnant women receive only $53 \%$ of calcium that should be in the diet [12].

The third most common musculoskeletal problem identified in our study was pedal edema that gradually increased towards the third trimester. This is in agreement with the results of another study in the literature, in which pedal edema was reported to be mostly seen in the third trimester [11]. The authors attributed this to the reduced muscle activity in the lower extremity, leading to the accumulation of fluid extravasation in the extracellular space. Pedal edema was also most frequently seen in pregnant women who led sedentary lives [13].

In our study, hand and wrist problems were reported by many patients. The most frequent problem was found to be carpal tunnel syndrome which was mostly detected in the third trimester. This can be due to the increased fluid retention during pregnancy. Carpal tunnel syndrome is usually seen in the second half of the pregnancy and regresses after delivery [14]. In a study conducted with pregnant women in India, carpal tunnel syndrome was most commonly seen in patients in their second trimester (9.3\%) [11]. The higher prevalence of carpal tunnel syndrome in our study can be due to the cultural differences and the fact 
that most women in the study area are housewives and they are more inclined to having hand and wrist problems due to carrying out household chores. Another hand-related problem found in our study was tendinitis, which has a higher incidence during pregnancy due to the increased fluid retention. In particular, we found 4 cases of de Quervain's tenosynovitis [15].

The musculoskeletal problems experienced during pregnancy significantly reduce the quality of life. Previous studies have shown that lower back pain considerably affects the daily life activities of pregnant women (such as housework, walking, working and sexual life) $[16,17]$. The early diagnosis and treatment of musculoskeletal problems is vital for improving the quality of life of pregnant women and preventing the development of chronic disorders. Especially, the economic load of chronic low back pain which is the most common cause of pain in our study has been reported to be quite high [18]. However, many pregnant women with these types of problems only seek medical help when these problems affect their daily life activities. This was also true for the participants of our study. Many did not consult a physician until their musculoskeletal complaints started to impair their ability to engage in daily life activities and quality of sleep. However, such problems that remain untreated during pregnancy can continue after delivery and lead to chronic disorders [19].

The main limitation of our study was its retrospective design and another limitation was the small sample. The strength of our study is presenting the most seen musculoskeletal problems in pregnancy according to trimester. Further prospective studies are needed to investigate both the most seen musculoskeletal problems in pregnancy and the efficacy of early treatment.

In this study, we identified the musculoskeletal problems that are most commonly seen in pregnancy according to different trimesters using the data from the patients admitted to Physical Medicine and Rehabilitation clinic. Monitoring these problems during routine physician checks in pregnancy can be an opportunity for early diagnosis and treatment.

Disclosures: There is no conflict of interest for all authors.

\section{Acknowledgements: None.}

\section{Funding: None.}

\section{References}

1. Kristiansson P, Svardsudd K, von Schoultz B. Back pain during pregnancy: a prospective study. Spine. 1996; 21(6):702-9. https://doi. org/10.1097/00007632-199603150-00008

2. Ayanniyi O, Sanya AO, Ogunlade SO, Oni-Orisan MO. Prevalence and pattern of back pain among pregnant women attending antenatal clinics in selected health care facilities. Afr J Biomed Res. 2009; 9(3):149-56. https://doi.org/10.4314/ajbr.v9i3.48898

3. Endresen EH. Pelvic pain and low back pain in pregnant women — an epidemiological study. Scand J Rheumatol. 1995; 24(3):135-41. https://doi.org/10.3109/03009749509099301

4. Ostgaard HC. Assessment and treatment of low back pain in working pregnant women. Semin. Perinatol. 1996; 20(1):61-9. https:// doi.org/10.1016/S0146-0005(96)80058-9

5. Heckman JD, Sassard R. Musculoskeletal considerations in pregnancy. J Bone Joint Surg Am—Series A. 1994; 76(11):1720-31. https://doi.org/10.2106/00004623-199411000-00018

6. Hammar M, Larsson L, Tegler L. Calcium treatment of leg cramps in pregnancy. Effect on clinical symptoms and total serum and ianized serum calcium concentrations. Acta Obstet Gynec Scand. 1981; 60:345-7. https://doi.org/10.3109/00016348109154121

7. Yurdoğlu C, Türker E, Örsel S. Hamilelikte görülen Ortopedik problemler. Acta Ortop Traumatol Turc. 1997; 31:34-6.

8. Martins RF, Silva JLP. Back pain is a major problem for many pregnant women. Rev Assoc Med Bras. 2005; 51(3):144-7. https://doi. org/10.1590/S0104-42302005000300014

9. Kristiansson P, Svardsudd K, Von Schoultz B. Serum relaxin, symphyseal pain, and back pain during pregnancy. Am J Obstet Gynecol. 1996; 175:1342-47. https://doi.org/10.1016/S0002-9378(96)70052-2

10. Ramachandra P, Maiya AG, Kumar P, Kamath A. Prevalence of musculoskeletal dysfunctions among Indian pregnant women. $J$. Pregnancy. 2015; 437105. https://doi.org/10.1155/2015/437105

11. Smagulova IE, Sharmanov T. Assessment of nutritional status of pregnant women living in Astana. J Clin Med Kaz. 2014; 2(32):38-42.

12. Sapsford R, Bullock-Saxton J, Markwell S. Women's Health: A Textbook for Physiotherapists. 1st edition. Bailliere Tindall. London, WB Saunders Company Ltd, 1997.

13. Wand JS. Carpal tunnel syndrome in pregnancy and lactation. W Hand Surg. 1990; 15:93-1. https://doi.org/10.1016/02667681(90)90057-B

14. Sehned ES, Joyce KM. De Quervain tenosynovitis in pregnant and postpartum women. Obstetr Gynec. 1986; 68:411-4. https://doi. org/10.1097/00006250-198609000-00025

15. Hansen A, Jensen DV, Wormslev M, Minck H, Johansen S, Larsen EC et al. Symptom-giving pelvic girdle relaxation in pregnancy. II: Symptoms and clinical signs. Acta Obstet Gynecol Scand. 1999; 78(2):111-5. https://doi.org/10.1034/j.1600-0412.1999.780207.x

16. Olsson C, Nilsson-Wikmar L. Health-related quality of life and physical ability among pregnant women with and without back pain in late pregnancy. Acta Obstet Gynecol Scand. 2004; 83(4):351-7. https://doi.org/10.1080/j.0001-6349.2004.00384.x

17. Yumusakhuylu Y, Baklacıoğlu HS, Aras H, Haliloğlu S, Selimoğlu E, İçağasığlu A. Chronic Low Back Pain. Bozok Medical Journal. 2018; 8(1):66-74.

18. Noren L, Ostgaard S, Johansson G, Ostgaard HC. Lumbar back and posterior pelvic pain during pregnancy: a 3-year follow-up. Eur Spine J. 2002; 11(3):267-71. https://doi.org/10.1007/s00586-001-0357-7 